\title{
NOVEL ELECTRODE STRUCTURE OF A MICRO FUEL CELL INTEGRATING A SERPENTINE FLOW FIELD CHANNEL
}

Didier Beloin St-Pierre, Mathieu Paquin, and Luc G. Fréchette

Université de Sherbrooke, Dept of Mechanical Engineering, Sherbrooke, Québec, Canada

\begin{abstract}
We demonstrated a fully-micromachined polymer electrolyte membrane fuel cell ( $\mu$ PEMFC) configuration that integrates the flow field with novel electrode structures done within a simple two-mask process. The silicon-based electrodes are designed to maximize platinum utilisation and are located within a serpentine flow channel for stable operation. This complements other work on $\mu$ PEMFC that has focused mostly on microfabricated flow fields and membranes, but less on novel electrode structures and their integration.
\end{abstract}

\section{INTRODUCTION}

Most of the conventional PEMFC electrodes are composed of Nafion ${ }^{\circledR}$ as the proton conductor, platinum as the catalyst, and carbon particles as the electric conductor. Mixed together, they create porous electrodes with ad-hoc tri-contacts sites in which the hydrogen and oxygen gas will diffuse. A tri-contact is a catalytic site where ions, molecules, and electrons are joined through respective conducting paths for the chemical reaction. The small scale of these reaction sites represents a good opportunity for microfabrication to optimise performances and ensure access to all tri-contacts sites. Microfabrication of the electrode structure has been studied by others [1, 2], although with less consideration of the ionic transport within the electrodes. MEMS research has also shown to be beneficial for the implementation of flow channels, gas diffusion layers (GDL) and the electrolyte membrane of microPEMFC $[3,4]$. (a)

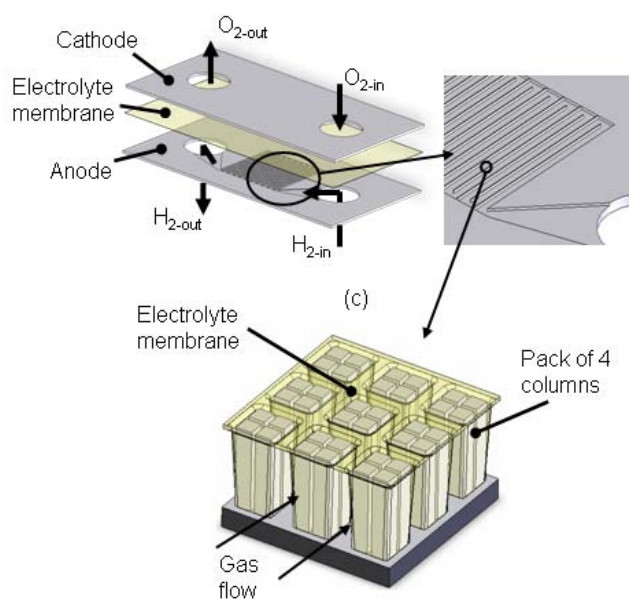

Figure 1: Configuration of the column matrix electrode structure with serpentine flow field. (a) Exploded view of the fuel cell showing the gas holes and gas flow path for $\mathrm{O}_{2}$ and $\mathrm{H}_{2}$ through the anode and the cathode. (b) Zoom on the serpentine flow field. Dimensions of the channel are $60 \mu \mathrm{m}$ deep by $400 \mu \mathrm{m}$ wide with $20 \mu \mathrm{m}$ thick walls. (c) Zoom on the columnar electrode structure in the serpentine channel. Columns are gathered in packs of four to ease wicking of Nafion ${ }^{\circledR}$ through capillary forces. Dimensions of the columns are $6 \mu \mathrm{m} \times 6 \mu \mathrm{m} x$ $60 \mu \mathrm{m}$. Separation between packs of 4 columns is $6 \mu \mathrm{m}$ and separation between adjacent columns is $2 \mu \mathrm{m}$.
In this work, we replace the ill-defined tri-contacts found in porous media with well defined catalytic sites and conduction paths implemented using microfabrication techniques. In our previous work, we designed a microfabricated electrode structure to optimize the use of expensive platinum catalyst [5]. Here, we integrated the electrodes structure within a microchannel flow field (Fig. 1), microfabricated the devices and successfully demonstrated their operation and the high usage of platinum area.

\section{DESIGN AND FABRICATION}

Two main aspects are novel in the micro-PEMFC presented here: the approach to integrate the electrodes within the flow channels and the electrode microstructure formed by DRIE and capillary wicking of a liquid polymer electrolyte. The process is shown in Fig. 2.

In opposition to conventional PEMFC for which flow field channels are placed on the surface of a gas diffusion layer over the electrodes, here the electrodes are integrated within the serpentine flow channel. This configuration, shown in Fig. 1, leads to a simple two-mask process where column-shaped electrodes are formed simultaneously with the flow channel, using DRIE (Fig. 3).

The electrodes themselves are formed of highly doped silicon columns coated sequentially with a sputtered Pt layer and a film of polymer electrolyte (Nafion $\left.{ }^{\circledR}\right)$. The electrolyte on the columns serves as the ionic conductor and is expected to be a major resistance for this configuration [5]. To alleviate this limitation, we gather columns into packs of four such that small gaps between them will increase capillary pressure and tend to improve wicking of a solution of Nafion ${ }^{\circledR}$ into the electrode structure (Fig. 3). This aims to allow better ionic conduction channels by having more Nafion ${ }^{\circledR}$ between the columns without blocking the gas flow. The process consists of soaking a Nafion ${ }^{\circledR}$ membrane into a solution of Nafion ${ }^{\circledR}$ at $5 \%$ (Liquion ${ }^{\circledR}$ ), then pressing it between two microfabricated electrodes to allow capillary forces to draw the solution into the column matrix. The device was then hot-pressed to bond and

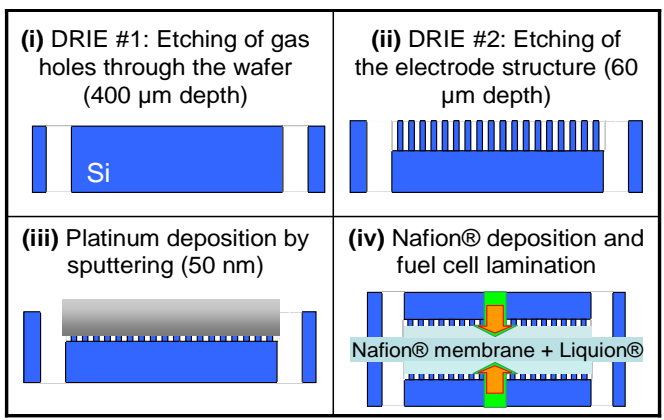

Figure 2: Cross-section view of the device showing the main steps involved in the fabrication. (i) Large gas holes are etched through the wafer by deep reactive ion etching (DRIE). (ii) A second DRIE step generates the column matrix and the serpentine flow field channel simultaneously. (iii) Platinum is sputtered over the column matrix structure. (iv) Solution of Nafion ${ }^{\circledR}$ (Liquion $\left.{ }^{\circledR}\right)$ is deposed by capillary force on the column matrix and a membrane is hot pressed between two microfabricated electrodes. 


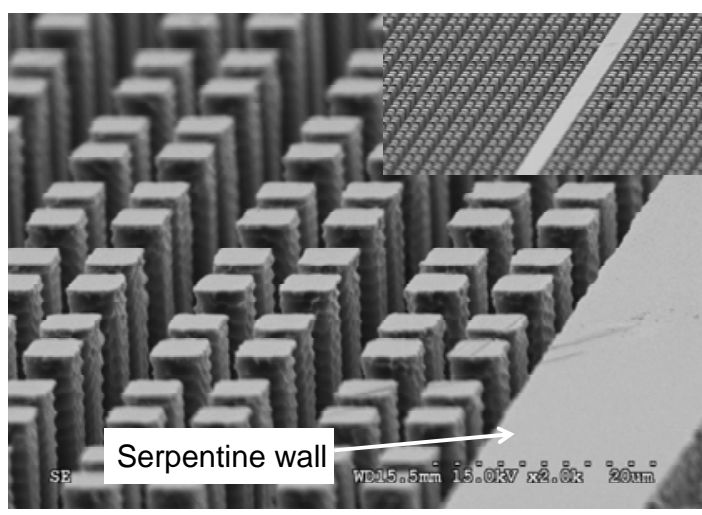

Figure 3: SEM image of the columns matrix electrode and the serpentine flow field formed by DRIE. Each electrode of $1 \mathrm{~cm}^{2}$ has a serpentine channel of $240 \mathrm{~mm}$ length and approximately 960,000 columns.

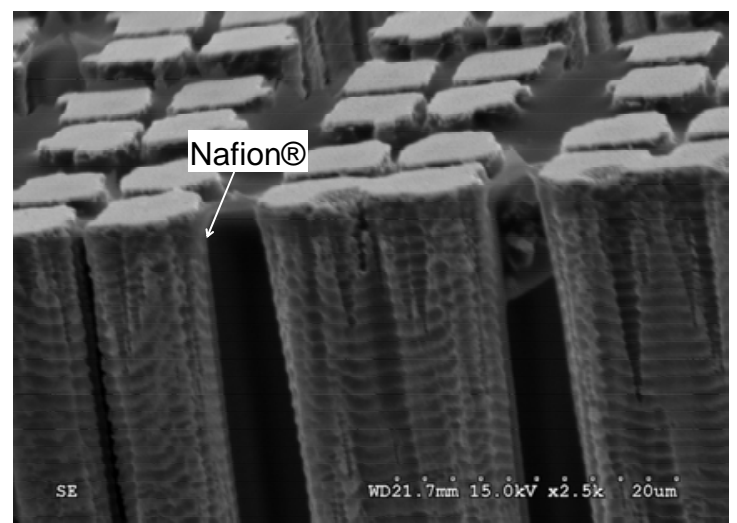

Figure 4: SEM image of the Liquion ${ }^{\circledR}$ deposition by capillary force on the column matrix structure after peeling off the Nafion ${ }^{\circledR}$ membrane for imaging. Nafion ${ }^{\circledR}$ appears to fill the smallest gaps between columns, but also some of the largest gaps, so further process improvement is required and higher levels of performance should be achievable.

seal the parts together at 6 psi and $100^{\circ} \mathrm{C}$ for 15 minutes and at $50^{\circ} \mathrm{C}$ for 30 minutes. Figure 4 shows the Nafion ${ }^{\circledR}$ coating on the columns.

\section{EXPERIMENTAL RESULTS}

A first configuration, consisting of a simple matrix of equally spaced columns, showed unstable performance, probably due to water management problems that also brought bad ionic conduction. Transient performance up to $37.4 \mathrm{~mW} / \mathrm{cm}^{2}$ and 123 $\mathrm{mA} / \mathrm{cm}^{2}$ was however achieved. The second configuration, with the serpentine channel and improved capillary wicking discussed above, showed stable and repeatable operation (Fig. 5), achieving a maximum power density of $13.5 \mathrm{~mW} / \mathrm{cm}^{2}$. The serpentine configuration was found to greatly improve the stability in operation, probably due to better gas flow control compared to a simple matrix of columns without the serpentine channel. When considering the power per unit area of platinum, we achieved up to $3.4 \mathrm{~mW} / \mathrm{cm}^{2}$ of Pt for the first device, which is slightly greater than conventional porous electrodes with $3.2 \mathrm{~mW} / \mathrm{cm}^{2}$ of Pt [6]. It should be noted that power per unit mass of Pt is however less interesting since a relatively thick layer of catalyst was applied; alternate nanocoatings of Pt should be considered instead of sputtering.

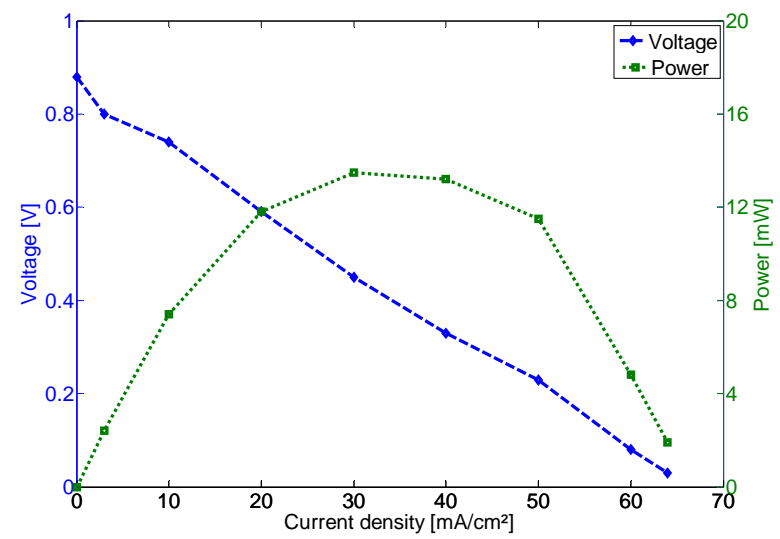

Figure 5: Experimental results showing polarisation and power curves for a device. Operating conditions: anode: $15 \mathrm{sccm}$ of humidify hydrogen at $55^{\circ} \mathrm{C}$ with a back pressure of 9 psi, cathode: $20 \mathrm{sccm}$ of humidify oxygen at $55^{\circ} \mathrm{C}$ with a back pressure of 8 psi, cell temperature of $30^{\circ} \mathrm{C}$. Linear polarisation curve suggests that mass transport problems are not the limiting problem and that electric or ionic resistance is the limiting parameter.

\section{CONCLUSION}

The simple fabrication process, the ability to tailor the electrode microstructures, the high $\mathrm{Pt}$ utilisation, and the interesting power levels achieved make this design promising and interesting for future research and applications in portable power generation. Future work should be done on Nafion ${ }^{\circledR}$ deposition to improve ionic conduction and minimise water management problems. This should reduce voltage loss in the fuel cell which is the biggest problem for the device at this point. Alternate deposition methods of the catalyst layers should also be considered.

\section{REFERENCES}

[1] W.Y. Sim, G.Y. Kim, S.S. Yang, "Fabrication of micro power source (MPS) using a micro direct methanol fuel cell ( $\mu \mathrm{DMFC})$ for the medical application”, Technical Digest of the 14th IEEE International Conference on MEMS, Interlaken, Switzerland, pp.341-344 (2001)

[2] J. Yeom, G.Z. Mozsgai, B.R. Flachsbart, et al., "Microfabrication and characterization of a silicon-based millimeter scale, PEM fuel cell operating with hydrogen, methanol, or formic acid", Sensors and Actuators B, 107, pp. 882-891 (2005)

[3] T. Pichonat, B. Gauthier-Manuel, "Recent developments in MEMS-based miniature fuel cells”, Microsyst Technol, 13, pp.1671-1678 (2007)

[4] G.J. La O, H. Jin In, E. Crumlin et al., "Recent adavances in microdevices for electrochemical energy conversion and storage”, International Journal of energy Research, 31, pp. 548-575 (2007)

[5] D.B. St-Pierre, M. Paquin, L.G. Fréchette, "Design and Microfabrication of a PEM Fuel Cell with Silicon-Supported Electrodes in a Column Matrix Configuration”, Technical Digest of the 2006 International Workshop on Micro and Nanotechnology for Power Generation and Energy Conversion Applications, Berkeley, U.S.A., pp. 93-96 (2006)

[6] H.A. Gasteiger, S.S. Kocha, B. Sompalli, et al., "Activity benchmarks and requirements for Pt, Pt-alloy, and non-Pt oxygen reduction catalysts for PEMFCs”, Applied Catalysis B: Environmental, 56, pp.9-35 (2004) 